\title{
Engineering and environmental geophysics at the millennium
}

\author{
Don W. Steeples*
}

\section{INTRODUCTION}

Near-surface geophysics is being applied to a broader spectrum of problems than ever before, and new application areas are arising continually. Currently, the tools used to examine the near-surface environment include a variety of noninvasive methods employing electrical, electromagnetic, or mechanical energy sources, along with passive techniques that measure the physical parameters of the earth. Some of the advances of recent years have emerged from breakthroughs in instrumentation and computer-processing techniques, and some have been driven by societal needs, such as the increasing demand for the accurate geophysical characterization of polluted sites. Other compelling factors, such as the ever-expanding need for groundwater, the enactment of laws that have spurred geophysical surveying for archaeological purposes, and the necessity for better soil-physics information in geotechnical engineering and agriculture, are present worldwide. For historical context, the reader is referred to an excellent review concerning the status of shallow exploration techniques in the mid-1980s (Dobecki and Romig, 1985).

Typically, the physical parameters measured directly during shallow surveys include gravitational and magnetic fields, electrical conductivity, elastic properties, transparency to and polarizability of electromagnetic waves, and natural gamma radiation. These measurements can then be used to infer the permeability, porosity, chemical constitution, stratigraphy, geologic structure, and various other properties of a volume of material near the earth's surface.

Although dozens of present-day and potential applications of near-surface geophysical methods exist (Table 1), such measurements and their geologic interpretations generally are applied for the following reasons:

1) To mitigate existing engineering and environmental problems, including earthquake-hazard analysis. Geophysical methods can be used to evaluate the extent of existing problems, predict the movement of subsurface pollutants, and guide exploratory drilling programs.

2) As input to the design parameters used to prevent future engineering and environmental problems. Increasingly, geophysical methods are being used prior to construction to help verify subsurface integrity at critical locations such as power plants, chemical plants, refineries, and waste-disposal facilities.

3) To explore for and optimize the production of resources, particularly water, coal, and minerals other than petroleum.

4) To enhance research and basic geologic and hydrologic knowledge.

The geophysical methods chosen to meet these objectives will vary according to a project's objectives, resolution requirements, available budget, and geological situation. For example, seismic methods are sensitive to the mechanical properties of earth materials but are relatively insensitive to the chemical makeup of these materials as well as the fluids they contain. In contrast, electrical methods are sensitive both to contained fluids and to the presence of magnetic or electrically conductive materials. However, in most cases the use of multiple geophysical methods at a site can provide better answers to relevant questions.

Following is a distillation of near-surface geophysical approaches as they exist today, although no doubt each reader could amplify this list from the perspective of his or her own knowledge and experience.

\section{BOREHOLE METHODS}

Many environmental and engineering geophysical technologies rely on borehole measurements because they offer the best resolution and decrease the effects of near-surface signal attenuation, formation heterogeneity, and some types of noise. The logging tools used in near-surface investigations are smalldiameter versions of the tools developed for the petroleum industry. Space limitations do not permit a useful discussion of borehole measurements; thus, the reader is referred to the scientific literature for additional information (e.g., Daniels and Keys, 1990; Howard, 1990).

\section{ACCEPTED OLDER METHODS}

\section{Electrical and electromagnetic (EM) methods}

Electrical resistivity methods directly gauge the bulk electrical resistance of the ground by measuring spatially varying voltages induced by the passage of an electrical current between 
electrodes implanted at the surface of the ground. The methods are sensitive to changes in the chemical content of pore fluids but do not provide direct information about the mechanical properties of the earth. Resistivity methods are particularly useful for tracking electrically conductive contaminants. Under some conditions these methods can be used to find geological faults and buried valleys, but usually not with the precision offered by seismic reflection techniques.

Table 1. Some uses of near-surface geophysical methods*.

Basic geology and hydrology

Aid in the study of sedimentology and stratigraphy

Assist in geologic mapping

Detect faults and karst conditions

Determine hydrological characteristics

Determine water-table depth

Map top of bedrock and bottom of landslides

Resource exploration and exploitation

Aid in the design of shallow-marine drilling platforms

Examine near-surface analogs of petroleum reservoirs

Examine the integrity of coal seams in advance of mining machines

Explore for coal, and metallic and other minerals

Make static corrections for deeper seismic surveys

Civil, mining, and earthquake engineering

Avoid surprises during tunneling, mining, and other underground activities

Define degree of ground stabilization and improvement after treatment

Detect and map underground utilities

Determine the "rippability" of rock

Determine the depth of scour around bridge pilings

Predict site amplification during earthquakes

Provide soil-strength estimates for dams and building foundations

Locate construction materials

Monitor ground movements and physical property changes over time

Provide shear-strength history during compaction

Monitor the strength of dams and levees

Environmental engineering

Detect the presence of disposal containers

Determine the integrity of underground storage facilities

Determine the nature of trench fill

Evaluate subsurface conditions around sinkholes

Identify infrastructure decay (e.g., leaking pipes and tanks; deterioration of bridge decks)

Investigate contaminant plumes

Locate imperfections, holes, and leaks in waste-containment barriers

Map old trenches used for waste disposal

Military engineering and law enforcement

Detect cavities

Detect unexploded ordnance

Monitor trafficability of roads and trails during military operations

Use as part of forensic investigations (e.g., locate weapons and graves)

Use in search-and-rescue operations (e.g., after avalanches, structure collapses, etc.)

\section{Other}

Explore archaeological sites

Map soil on the scale of meters to tens of meters for precision agricultural uses

*Some entries such as cavity detection also could be listed under several branches of engineering. This list is not intended to be exhaustive but to provide typical examples.
Resistivity techniques normally have a substantial cost advantage over seismic methods, however. The recent development of systems that rely on multichannel electrical cables that are similar to seismic cables has increased the flexibility and the rate of fieldwork characteristic of resistivity surveys. Interpreting electrical and EM surveys often involves an inversion routine to produce a model that fits the data (e.g., Zohdy, 1989; Ellis and Oldenburg, 1994). Resistivity methods are being replaced by EM methods because they can provide information that is approximately equivalent more rapidly but without the necessity of using electrodes in contact with the ground.

The induced polarization (IP) method is related to the resistivity method; however, in the IP method the earth's delayed response to an induced current is analyzed. Think of the "P" in IP as representing persistence in terms of the length of time the earth remains disturbed electrically after the disturbing function has been removed. In an electronic sense, the discharge rate of a portion of the earth is similar to that of a capacitor. The rate of decay of the induced voltage is dependent on the mobility of the ions in the charged volume. The ions in clays, for example, are highly mobile. Measurements can be made either in the time domain, with voltage as a function of time, or in the frequency domain, where the phase delays of various frequencies are measured. The transmitter and receiver can be connected, or highly accurate clocks can be synchronized at the start of each day to determine the amount of delay for each frequency reaching the voltage electrodes. Frequencies commonly range between about $0.05 \mathrm{~Hz}$ and $1 \mathrm{kHz}$. This method is heavily used in sulfide exploration and has been used in some localities for groundwater exploration. Ward et al. (1995) presented some recommendations for potentially fruitful areas for IP research.

The spontaneous potential $(S P)$ method provides a measure of the natural voltage in the earth resulting from electrochemical activity. Natural voltages rarely exceed $100 \mathrm{mV}$, and they usually average out to zero over distances a few times larger than any anomalies that may be present. Fluid, ions, or heat moving in the earth can generate spontaneous potentials. Because a passive technique is used to record these small voltages, the source current or configuration remains unchanged. And because the voltages are small, the signals are vulnerable to noise from powerlines, pipelines, electrical storms, and other environmental noise sources. One of the problems with $\mathrm{SP}$ techniques is that the noise level sometimes prevents the repeatability of the measurements. The principal use of SP methods has been to monitor subsurface water movement (i.e., observing a moving conductor in a magnetic field), although the method has been used with some success in geothermal exploration as well. In the geothermal case, in addition to the voltage from movement of geothermal fluids, mineralized waters may induce chemical reactions. Mapping the concentration gradients of chemically active leachates also may be another possible use of SP surveys. Data may be interpreted by generating contour maps of voltages or by using more quantitative means involving calculations that rely on geometrical shapes similar to those used in magnetic and gravity studies. Corwin (1990) provides the fundamentals of using SP methods in near-surface application.

Electromagnetic methods are becoming more popular in the environmental geophysics business. They measure the electromagnetic fields associated with the underground alternating currents induced by a primary underground field. 
In active EM surveying, the primary field is induced by passing an electrical current through a coil. This field spreads out in three dimensions and induces the flow of currents through underground conductors according to the physical laws of electromagnetic induction. A secondary electromagnetic field is then induced, which in turn distorts the primary field, and the ensuing final field is sensed by a receiving coil. The sensed field differs in intensity, phase, and direction from the primary field, thus revealing information about subsurface conductivity. These methods have a major advantage over direct-current (dc) resistivity because they do not require placing electrodes in the ground. Indeed, the surveys can sometimes be conducted from low-flying aircraft. One recent development in airborne EM offers the advantages of increased surveying speed and access to polluted, dangerous, or inaccessible areas via small (maximum dimension 1-2 m) unmanned aircraft. However, airborne surveys also have disadvantages, including limited separation between the source and receiver coils and a higher noise level caused by the movement of the coils through the earth's magnetic field. McNeill (1990) provides both the practical background and the theoretical basis for EM methods.

In passive EM surveying, the earth's natural electromagnetic fields are used to provide the variations in the electric field. Among these is the audio-frequency magnetic field (AFMAG) technique, which uses electric fields generated by distant lightning flashes as a source. Another passive procedure uses very low radio frequencies (VLF). The VLF method relies upon the $15-25 \mathrm{kHz}$ electric field from distant, powerful radio transmitters used to communicate with submarines.

\section{Potential fields methods}

Magnetic surveys, particularly those that employ magnetic gradiometry, are useful in shallow studies and in the search for buried metal objects such as steel drums. Gradiometry consists of taking simultaneous readings from two magnetometers spaced a few decimeters to a few meters apart and then analyzing the difference (the magnetic gradient) between simultaneous readings of the instruments. Magnetic surveys are also useful in mapping faults, locating magnetic bodies, and estimating the depth to magnetic earth materials. Such surveys are used to detect variations in the magnetite content of rocks and unconsolidated materials; thus, they can detect changes in some types of igneous rocks and other geologic structures. They are used also at contaminated sites to measure the perturbation of the earth's magnetic field caused by buried ferrous metal objects such as steel drums, the ferrous metal waste in landfills, and iron pipes (e.g., Roberts et al., 1990a). Magnetic surveying is a relatively mature field, although improvements in data precision and collection rates continue to evolve, and vector recording of the field could be useful.

Techniques involving gravity measure minuscule changes in the gravitational field of the earth. Microgravity surveys sometimes are used in shallow geophysical exploration, particularly where a high contrast in density occurs between bedrock and an overlying alluvium, for example. These surveys use gravity meters with a sensitivity of $1 \mu \mathrm{Gal}$ along a profile line or a grid with typical spacing of 1-10 m. Relative to the earth's gravitational field, the sensitivity of microgravity measurements is one part in $10^{9}$. After correcting the data for all known effects that can cause changes in gravity, such as earth tides, in- strument drift, latitudinal variation, variations in elevation between measurement stations, and the effects of terrain features, the remaining map of gravity anomalies reflects the variations caused by lateral density contrasts. Several geologic conditions including cavities, faults, folds, dipping layers, and lateral intralayer heterogeneity can cause anomalies in microgravity, as do buried manmade features such as trenches, tunnels, disposal containers, and incipient subsidence problems (e.g., Roberts et al., 1990b; Yule et al., 1998). Microgravity methods cannot detect contaminants directly, although they are sensitive to fluid loss from the near-surface layers. Gravity gradiometry (Butler, 1984) may increase in popularity when fast, accurate, and cheap gravity meters have been developed, particularly when used with an accurate global positioning system (GPS).

\section{Near-surface seismic methods}

The seismic refraction method has been used in engineering and geotechnical investigations for several decades. The reflection method, however, was not adapted for use shallower than $30 \mathrm{~m}$ until the mid-1980s. In some cases seismic reflections can be used at depths less than 2 m (Baker et al., 1999), but these new capabilities are not yet widely known outside the relatively small but growing community of environmental geophysicists.

Since 1980, significant strides have been made in nearsurface $P$-wave seismic-reflection surveying (Hunter et al., 1984; Steeples and Miller, 1990), shallow-seismic refraction methods (Palmer, 1980; Lankston and Lankston, 1986), and surface-wave techniques (Stokoe et al., 1994; Park et al., 1999; Xia et al., 1999). The use of shallow $S$-wave reflections has not been widespread, but a few examples can be found in the literature (e. g., Hasbrouck, 1991; Goforth and Hayward, 1992). Separating the $S$-wave reflections on seismograms from the surface waves that usually appear at the same time has been difficult.

Tomographic surveys use the same mathematical approach that has been used so successfully by the medical profession in the development of the three-dimensional (3-D) X-ray imaging within the human body commonly known as the CAT (computed axial tomography) scan. The technique depends on measuring the traveltimes of large numbers of seismic raypaths through a body of earth material. Tomography has been used to study the interior of the earth from scales of thousands of kilometers to tens of meters (e.g., Clayton and Stolt, 1981; Humphreys et al., 1994).

In future applications, combining $P$ - and $S$-wave refraction methods will raise new possibilities (Hasbrouck, 1987). Among these is measuring the elastic parameters of rocks by virtue of their $P$-wave and $S$-wave velocities combined with density readings derived from gravity surveys or borehole density logs. With these three pieces of information, Poisson's ratio, Young's modulus, and the shear modulus can be computed easily. When these elastic constants have been measured, rock types can be identified and a preliminary determination of pore-space fluid content usually is possible (Domenico and Danbom, 1987).

The recent advent of seismic hardware capable of collecting as well as processing high-resolution, near-surface data opens up new opportunities for three-component recording and multimode analysis. The capabilities of seismic methods involving target depths shallower than $30 \mathrm{~m}$ can be extended by analyzing the seismic wave types generally discarded by classical seismic reflection surveyors during the processing, analysis, and 
interpretation of data. Specifically, examining the near-surface broadband seismic wavefield is becoming possible by using three vector components rather than one and analyzing multiple types (modes) of seismic waves rather than $P$-waves alone.

\section{Radiometric techniques}

Radiometric techniques measure the radiation emitted by radioactive isotopes. The methods can be used to explore for radioactive ores or find radioactive contaminants. Spectral gamma methods are useful in identifying specific isotopes that occur within a meter or two of the earth's surface, and these methods may be useful in locating natural radioactive hazards, such as radon gas sources. Nielson et al. (1990) present a review of natural gamma and radon emanation techniques.

\section{SOME NEWER METHODS}

\section{Ground-penetrating radar (GPR)}

Among the more recently developed methods is shallow ground-penetrating radar (e.g., Davis and Annan, 1989). In many areas, GPR is considered the method of choice for exploring the upper few meters of the earth's subsurface. To perform a GPR survey, a source of microwave radiation is beamed into the earth at a known time. The time required for the waves to echo back to the surface is used to calculate the depth to various layers in the earth, although velocity determination is a critical factor (Tillard and Dubois, 1995). In many ways, GPR is similar to seismic reflection. Data are displayed in a format that is (or can be) identical to seismic sections. Paradoxically, the environments in which the two techniques work well tend to be mutually exclusive. The GPR method works best under dry conditions and in the absence of clays or other electrically conducting earth materials because electromagnetic radiation will not penetrate conductors. For example, dry quartzitic sand is an excellent medium for the transmission of radar waves beneath the earth's surface, whereas seismic waves can be transmitted nicely through electrically conductive clays saturated with water but are quickly attenuated in dry sand.

\section{Nuclear magnetic resonance (NMR)}

Nuclear magnetic resonance was introduced as a laboratory measurement to investigate molecular-scale phenomena by monitoring the change in the energy state of nuclei. A radiofrequency pulse excites the nuclei to a higher energy state. Then their return to the original state is monitored, modeled as a sum of exponential decays, and recorded as two relaxation-time constants. The relaxation constant, $T_{1}$, is associated with the longitudinal component of the magnetization, and $T_{2}$ is taken from the transverse component. The NMR technique can be used to study any nuclei having an intrinsic magnetic moment, such as hydrogen or carbon-13. Numerous reviews of NMR theory are available in the scientific literature (e.g., McMurray, 1984).

Of specific interest to those in the earth sciences is proton NMR, which responds to the state of hydrogen nuclei in the ground. Referring to the near-surface geophysical use of NMR as "imaging" may be premature, however. A Russian team (Semenov et al., 1988) developed the "hydroscope" used to collect geophysical NMR data. This system consists of a trans- mitter and receiver in which antennas approach $100 \mathrm{~m}$ in diameter, which places a lower limit on horizontal spatial resolution. The amplitude of the initial magnetization is proportional to the number of hydrogen nuclei in the sample, which in turn is proportional to the total volume of water present as a function of depth.

After the transmitter is turned off, the relaxation time will contain information about the grain size of the water-saturated rock. When a porous material contains water, the relaxation time is a function of two mechanisms: relaxation in the bulk fluid and relaxation on the solid pore surfaces. Surface relaxation is the faster mechanism and dominates the response, which leads to a relationship between relaxation time and the ratio of the pore's surface area to volume, which is a function of grain size. Shirov et al. (1991) estimated grain size using an empirical correlation between rock type and decay time. An inversion method that minimizes the misfit between the calculated and measured responses is used to extract both the total amplitude and the relaxation-time constants.

Bryar et al. (2000) and Knight et al. (1999) examined the NMR effects of paramagnetic species (such as Fe3+) that cause dramatic changes in $T_{2}$ so that the direct link to the ratio of the surface area to volume breaks down, thus making it much more difficult to obtain estimates of permeability. For example, two sands whose grain size, pore size, and distribution are identical could appear to have different permeabilites when one has a high $\mathrm{Fe} 3+$ content and the other does not. Hence, in near-surface applications the variation in the content of $\mathrm{Fe} 3+$ and other paramagnetic species could complicate or negate permeability estimates based on NMR data. Depending upon the specific location of the $\mathrm{Fe} 3+$ (i.e., in pore water, adsorbed to the solid phase, or in a solid mineral grain) $T_{2}$ would be affected, but to a different extent.

\section{THE FUTURE}

The future of near-surface geophysical methods is bright. These methods will be used to meet engineering, environmental, and mineral resource needs that will exist long after the last barrel of oil has been pumped from the ground. The advent of precision agriculture, in which inputs and yields are matched against GPS-determined locations, demands information about soil physics and chemistry as additional data for analysis using geographic information systems (GIS). Furthermore, many near-surface geophysical techniques are still developing rapidly. Today, for example, a single receiving antenna is used to collect almost all GPR data, but multiantenna GPR could have the potential to enhance GPR capabilities in much the same way that common-midpoint surveying improved the seismic reflection method in the 1960s.

Shallow seismic methods could benefit greatly from an increased analysis of surface waves (e.g., Park et al., 1999; Xia et al., 1999). The petroleum industry has put great effort into removing surface waves from seismic reflection data, but relatively little effort has gone into enhancing and analyzing those waves, even though they are recorded as a normal part of the information gathered using shallow seismic reflection methods.

Every near-surface geophysical method can benefit from increased automation-from robots roving over the ground to model airplanes aloft carrying microsensing devices over hazardous or polluted areas. Even near-surface seismology 
may be amenable to the automatic emplacement of geophones (Steeples et al., 1999).

At present, the full waveform inversion of both seismic and GPR data is only feasible for small data sets because of the immense computational resources required. When computing costs have decreased sufficiently, these inversions may become commonplace. One caveat, however, is that the inversion process treats noise with the same reverence that it treats data. When noise is present in shallow seismic or GPR data, a datainversion routine may produce artifacts related to its attempt to invert the noise.

Using geophysics to sense underground microbiological impacts remains a largely unexplored domain (Ghiorse, 1997). This area may achieve greater importance when the ability to restore the underground environment using microbes has been developed sufficiently. Likewise, if underground microbial mining is realized, geophysical methods of monitoring those processes will be needed. Near-surface geophysics has the capacity to measure changes continuously, with high spatial resolution, over time (Brewster et al., 1995), which could allow the monitoring of underground biological activity.

The areas of resolution and bandwidth in geophysical procedures must continue to be improved. Faster and more reliable methods of data processing would be useful as well, with special attention given to decreasing the ambiguities and uncertainties that now plague data interpretation. Furthermore, reducing costs will always be desirable. Cost reductions could be accomplished by combining robotics, automation, expert systems, and the use of miniature aircraft. Education concerning these methods must be improved along with the smooth transfer of technology from its developers to users and potential beneficiaries.

Lastly, near-surface geophysics can have an impact on publicpolicy issues. Several of the applications shown in Table 1 bear on societal health and safety. Among these are earthquake hazard mitigation, pollution abatement, and even the question of global warming. Late in the twentieth century, the potential relationships between near-surface geophysics and public safety led to a trend toward the professional registration of geophysicists.

\section{REFERENCES}

Baker, G. S., Schmeissner, C., and Steeples, D. W., 1999, Seismic reflections from depths of less than two meters: Geophys. Res. Lett., 26, 279-282.

Brewster, M. L., Annan, A. P., Greenhouse, J. P., Kueper, B. H., Olhoeft, G. R., Redman, J. D., and Sander, K. A.,1995, Observed migration of a controlled DNAPL release by geophysical methods: Groundwater, a controlled

Bryar, T. R., Daughney, C. J., and Knight, R. J., 2000, Paramagnetic effects of iron (III) species on nuclear magnetic relaxation of fluid protons in porous media: J. Magnetic Resonance, 142, 74-85.

Butler, D. K., 1984, Interval gravity-gradient determination concepts: Geophysics, 49, 828-832.

Clayton, R. W., and Stolt, R. H. 1981, A Born-WKBJ inversion method for acoustic reflection data: Geophysics, 46, 1559-1567.

Corwin, R. F., 1990 The self-potential method for environmental and engineering applications in Ward, S. H., Ed., Geotechnical and environmental geophysics 1: Soc. Expl. Geophys. 127-146.

Daniels, J. J., and Keys, W. S. 1990, Geophysical well logging for evaluating hazardous waste sites, in Ward, S. H., Ed., Geotechnical and environmental geophysics 1: Soc. Expl. Geophys., 263-286.

Davis, J. L., and Annan, A. P., 1989, Ground-penetrating radar for highresolution mapping of soil and rock stratigraphy: Geophys. Prosp., 37, 531-552.

Dobecki, T. L., and Romig, P. R., 1985, Geotechnical and groundwater geophysics: Geophysics, 50, 2621-2636.
Domenico, S. N., and Danbom, S. H., 1987, Shear-wave technology in petroleum exploration-Past, current, and future, in Danbom, $\mathrm{S}$ H., and Domenico, S. N., Eds., Shear-wave exploration: Soc. Expl. Geophys., 3-18.

Ellis, R. G., and Oldenburg, S. W., 1994, The pole-pole 3-D DCresistivity inverse problem: A conjugate-gradient approach: Geophys. J. Internat., 119, 187-194.

Ghiorse, W. C., 1997, Subterranean life: Science, 275, 789-790.

Goforth, T., and Hayward, C., 1992, Seismic reflection investigations of a bedrock surface buried under alluvium: Geophysics, 57, 12171227.

Hasbrouck, W. P., 1987, Hammer impact, shear-wave studies: in Danbom, S. H., and Domenico, S. N., Eds., Shear-wave exploration: Soc. Expl. Geophys., 97-121.

1991, Four shallow-depth, shear-wave feasibility studies: Geophysics, 56, 1875-1885.

Howard, K. W. F., 1990, Geophysical well logging methods for detection and characterization of fractures in hard rocks, in, Ward, S H., Eds., Geotechnical and environmental geophysics 1: Soc. Expl Geophys., 287-308.

Humphreys, G., Clayton, R. W., and Hager, B. H., 1984, A tomographic image of mantle structure beneath southern California: Geophys. Res. Lett., 11, 625-627.

Hunter, J. A., Pullan, S. E., Burns, R. A., Gagne, R. M., and Good, R. L., 1984, Shallow seismic reflection mapping of the overburdenbedrock interface with the engineering seismograph-Some simple techniques: Geophysics, 49, 1381-1385.

Knight, R., Bryar, T., and Daughney, C., 1999, Laboratory studies to assess the use of nuclear magnetic resonance for near-surface applications: 69th Ann. Internat. Mtg., Soc. Expl. Geophys., Expanded Abstracts, 465-468.

Lankston, R. W., and Lankston, M. M., 1986, Obtaining multilayer reciprocal times through phantoming: Geophysics, 51, 45-49.

McMurray, J., 1984 Organic chemistry: Brooks/Cole Publishing Co.

McNeill, J. D., 1990, Use of electromagnetic methods for groundwater studies, in Ward, S. H., Ed., Geotechnical and environmental geophysics 1: Soc. Expl. Geophys., 191-218.

Nielson, D. L., Linpei, C., and Ward, S. H., 1990, Gamma-ray spectrometry and radon emanometry in environmental geophysics, in Ward, S. H., Ed., Geotechnical and environmental geophysics 1: Soc. Expl. Geophys., 219-250.

Palmer, D., 1980. The generalized reciprocal method of seismic refraction interpretation: Soc. Expl. Geophys.

Park, C. B., Miller, R. D., and Xia, J., 1999, Multichannel analysis of surface waves: Geophysics, 64, 800-808.

Roberts, R. L., Hinze, W. J., and Leap, D. I. 1990a, Data enhancement procedures on magnetic data from landfill investigations, in Ward, S. H., Ed., Geotechnical and environmental geophysics, 2: Soc. Expl. Geophys. 261-266.

Roberts, R. L., Hinze, W. J., and Leap, D. I., 1990b, Application of the gravity method to the investigation of a landfill in glaciated midcontinent, U. S. A. in Ward, S. H. Ed., Geotechnical and environmental geophysics, 2: Soc. Expl. Geophys., 253-260.

Semenov et al., 1988, A device for measurement of underground mineral parameters: USSR Patent 1540515

Shirov, M., Legchenko, A., and Creer, G., 1991, A new direct noninvasive ground water detection technology for Australia: Expl. Geophys., 22, 333-338.

Steeples, D. W., Baker, G. S., and Schmeissner, C., 1999, Toward the autojuggie: Planting 72 geophones in 2 seconds: Geophys. Res. Lett., 26, 1085-1088.

Steeples, D. W., and Miller, R. D., 1990, Seismic-reflection methods applied to engineering, environmental, and ground-water problems, in Ward, S. H., Ed., Geotechnical and environmental geophysics 1: Soc. Expl. Geophys., 1-30.

Stokoe, K. H., Wright, S. G., Barg, S. A., and Roësact, J. M., 1994, Characterization of geotechnical sites by SASW method, in Woods, R. D., Ed., Geophysical characterization of sites: Oxford Publishers, New Delhi.

Tillard, S., and Dubois, J. C., 1995, Analysis of GPR data: Wave propagation velocity determination: J. Appl. Geophys., 33, 77-91.

Ward, S. H., Sternberg, B. K., LaBrecque, D. J., and Poulton, M. M. 1995, Recommendations for IP Research: The Leading Edge, 14 243-247.

Xia, J., Miller, R. D., and Park, C. B., 1999, Estimation of near-surface shear-wave velocity by inversion of Rayleigh waves: Geophysics, $\mathbf{6 4}$, 691-700.

Yule, D. E., Sharp, M. K., and Butler, D. K., 1998, Microgravity investigations of foundation conditions: Geophysics, $\mathbf{6 3}, 95-103$.

Zohdy, A. A. R., 1989, A new method for the automatic interpretation of Schlumberger and Wenner sounding curves: Geophysics, 54, 245253. 